\title{
Dualismo no Campo e Desigualdades Internas na Agricultura Familiar Brasileira ${ }^{1}$
}

\author{
Joacir Rufino de Aquino², Marcio Gazolla ${ }^{3}$ e Sergio Schneider ${ }^{4}$
}

Resumo: O objetivo desse artigo é identificar os elementos característicos da estrutura agropecuária brasileira e demonstrar a marcante desigualdade presente na agricultura familiar do País. Para tanto, foi realizada uma ampla pesquisa bibliográfica sobre o tema, bem como um levantamento de dados estatísticos oficiais relacionados ao perfil produtivo do setor e à oferta de crédito rural. De maneira geral, o trabalho mostra que há um marcante dualismo econômico e político entre a agricultura familiar e a agricultura patronal/agronegócio em constante disputa por fundos públicos no Brasil, levando à adoção de visões generalizantes pautadas em médias estatísticas dos indicadores censitários que tendem a desviar o foco das desigualdades gritantes prevalecentes no campo nacional. Em relação à agricultura familiar, apesar das melhorias na distribuição de renda e outros avanços verificados no limiar do século XXI, nota-se uma significativa heterogeneidade e desigualdade produtiva no interior do segmento, em que predomina um vasto contingente de produtores pobres ou extremamente pobres. Na base desse quadro social, frequentemente negligenciado nas análises que buscam ressaltar as virtudes da categoria de forma agregada a partir dos dados censitários, está uma herança histórica de diferenciação social, que se mantém e se agrava ao longo do tempo, devido, entre outros fatores, ao privilegiamento dos setores mais capitalizados do segmento na distribuição do crédito rural do Pronaf.

Palavras-chaves: agricultura familiar, agronegócio, desigualdades econômicas, Pronaf.

Abstract: The purpose of this article is to identify the characteristic elements of Brazilian agricultural structure and demonstrate the marked inequality present in family farming in the country. For this, research on the bibliography was held on the subject in recent years, as well as a survey of official statistics related to the productive sector profile and the provision of rural credit. Overall, the study shows that there is a remarkable economic and political dualism between family farmers and commercial farmers/agribusiness in constant

1. Data de submissão: 28 de agosto de 2017. Data de aceite: 22 de dezembro de 2017.

2. Universidade do Estado do Rio Grande do Norte (UERN). Assú, Rio Grande do Norte, Brasil. E-mail: joaciraquino@yahoo.com.br

3. Universidade Tecnológica Federal do Paraná (UTFPR-PPGDR). Pato Branco, Paraná, Brasil. E-mail: marciogazolla1@gmail.com

4. Universidade Federal do Rio Grande do Sul (UFRGS). Porto Alegre, Rio Grande do Sul, Brasil. E-mail: schneide@ufrgs.br 
competition for public funds in Brazil, leading to adoption of generalizing visions guided on statistical averages of census numbers that tend to shift the focus of the prevailing glaring inequalities in the national field. In relation to family farming, despite improvements in the distribution of monetary income recorded in the twenty-first century approaches, there is a significant heterogeneity and productive inequality within the segment, dominated by a vast contingent of poor or extremely poor farmers. On the basis of this framework, often overlooked in analyses that seek to emphasize the virtues of the category of aggregate from the census data, there is a historical heritage of social differentiation, which maintains and worsens over time, due, among other factors, to the recent privileging of the sectors most capitalized segment of the distribution of rural Pronaf credit.

Key-words: family farming, agribusiness, economic inequalities, Pronaf.

Classificação JEL: Q10, Q15, Q18.

DOI: http://dx.doi.org/10.1590/1234-56781806-94790560108

\section{Introdução}

O debate acadêmico sobre a agricultura familiar no Brasil se intensificou na última década do século XX, a partir das obras de Veiga (1991), Abramovay (1992) e Lamarche (1993), que demonstraram a importância socioeconômica dessa forma de produção e trabalho no mundo, especialmente na Europa, nos EUA e também em nosso País. Na esteira destas publicações, os estudos pioneiros do Projeto de Cooperação FAO/Incra $(1995,1996,2000)$ contribuíram para incrementar a discussão relativa ao tema por meio do desenvolvimento de uma metodologia específica de tabulação dos dados dos censos agropecuários de 1985 e 1995/96, abrindo a possibilidade de classificação da agricultura familiar e da agricultura patronal no universo de estabelecimentos agropecuários.

Mais recentemente, o Censo Agropecuário 2006, realizado pelo IBGE, introduziu uma novidade em relação às edições anteriores, haja vista que, pela primeira vez na história do citado levantamento, foram empregadas variáveis algébricas que permitiram identificar diretamente nas estatísticas oficiais os setores componentes das "duas agriculturas brasileiras" através da aplicação dos critérios da Lei da Agricultura Familiar (Lei n. 11.326/2006). Além disso, o mesmo apresentou outros elementos, como o mapeamento de atividades importantes no meio rural até então não recenseadas (a exemplo da agroindústria rural e da produção orgânica), rendas não agrícolas, financiamentos rural e aspectos demográficos dos produtores de diferentes categorias (SOARES, 2015).
A divulgação dos dados da primeira apuração do Censo Agropecuário 2006, no final de 2009, provocou entusiasmo entre os movimentos sociais do campo. $\mathrm{O}$ referido levantamento confirmou que a agricultura familiar, de forma agregada, é o segmento social predominante no rural brasileiro, respondendo pela maioria absoluta das ocupações e pela produção da maior parte dos alimentos consumidos no mercado doméstico (DEL GROSSI e MARQUES, 2010; FRANÇA, DEL GROSSI e MARQUES, 2009; IBGE, 2009). Tais evidências, pautadas na média dos indicadores estatísticos, fortaleceram a luta do movimento sindical e do Ministério do Desenvolvimento Agrário (MDA) à época em defesa da ampliação do escopo das políticas públicas para a categoria, sendo referenciadas até o presente para exaltar as suas virtudes socioeconômicas de maneira conjunta (ANANIAS, 2015; SAF/MDA, 2015; SEIBT et al., 2015).

Em nível internacional, os dados agregados do Censo Agropecuário de 2006 também têm sido utilizados em várias publicações para respaldar a representatividade da agricultura familiar nacional, que frequentemente é apresentada como um "ser único e homogêneo" (CEPAL/FAO/IICA, 2013; FAO, 2014a, 2015; LOWDER, SKOET e SINGH, 2014). Em 2014,

5. O MDA foi criado em 1999 pelo governo FHC e, durante as gestões de Lula e Dilma Rousseff, se converteu no principal órgão operador das políticas de apoio à agricultura familiar no Brasil, sendo extinto pelo presidente interino Michel Temer, em 2016 (BIANCHINI, 2015; MATTEI, 2016). A análise desenvolvida aqui, contudo, não explora os acontecimentos recentes restringindo-se até 2015, quando o referido Ministério ainda estava em pleno funcionamento. 
por ocasião das comemorações do Ano Internacional da Agricultura Familiar, promovido pela Organização das Nações Unidas para a Agricultura e Alimentação (FAO), o Brasil aparece seguidamente como um caso exemplar no contexto latino-americano, em que o Estado prioriza e apoia o segmento em permanente disputa com o agronegócio exportador (FAO, 2014b; LOWDER, SKOET e RANEY, 2016).

Praticamente todos os estudos supracitados, tanto os nacionais como os elaborados por observadores externos, se utilizam de percentuais médios dos indicadores censitários para caracterizar o universo de agricultores familiares e ressaltar suas qualidades. Com efeito, transmitia-se a ideia de que a agricultura familiar era prioridade do governo brasileiro e que o setor representaria um bloco ou segmento social coeso de produtores. Ademais, a ascensão da chamada "classe média rural" foi percebida como uma espécie de ponto de inflexão nas contradições do modelo agrícola historicamente resistente à mudanças (MDA/SAF/PRONAF, 2013; NERI, MELO e MONTE, 2012; SAF/MDA, 2015). Esse tipo de abordagem ancorada em uma visão generalista e na expansão dos padrões de consumo do setor, porém, tem um alcance analítico extremamente limitado. Isso porque não considera o peso do viés concentrador da política agrícola nacional e muito menos a precariedade produtiva prevalecente no interior do segmento familiar.

De fato, embora alguns analistas tenham alertado sobre a importância dos estudos rurais ajustarem suas lentes para um "olhar interno da agricultura familiar" (BELIK, 2015; DELGADO, 2005; LONG e PLOEG, 1994; NEVES, 2007; NIEDERLE, FIALHO e CONTERATO, 2014; SCHNEIDER E CASSOL, 2014; WANDERLEY, 2014), as investigações pouco têm avançado nessa direção. Na verdade, o que se observa é a predominância de um debate polarizado entre os defensores da agricultura familiar e do desenvolvimento rural de um lado, e, do outro, os que contra-argumentam reafirmando as teses sobre a "superioridade tecnológica e produtiva" das formas não familiares de produção pautadas no trabalho assalariado e no consumo intensivo de insumos modernos (ALVES e ROCHA, 2010; ALVES e CONTINI, 2014; BUAINAIN et al., 2013; MATTEI, 2014a, 2014b; NAVARRO e PEDROSO, 2014). Faz-se necessário, então, compreender de maneira mais detalhada essas questões e buscar preencher as lacunas deixadas pelas generalizações maniqueístas, que escondem mais do que revelam as especificidades da realidade social.

Nesse sentido, o presente artigo procura fazer uma releitura crítica das estatísticas censitárias brasileiras, a partir de "tabulações especiais" recalculadas e publicadas na base de dados do Sidra/IBGE em 2012, objetivando demonstrar as particularidades da estrutura agropecuária nacional que ainda apresenta como traço característico as disparidades econômicas entre os segmentos sociais. Especificamente, o trabalho discute que a dicotomia familiar versus patronal tem encoberto a grande heterogeneidade e desigualdade (produtiva) que existe no interior do setor familiar. Adicionalmente, busca explicar que a opção pela utilização da média estatística para apresentar as virtudes da categoria familiar se justifica na disputa por fundos públicos, travada entre o MDA e os outros órgãos governamentais no período que se estende até 2015, mas contribui para obscurecer as diferenças existentes no seu interior, que tendem a se manter e a se agravar devido ao caráter seletivo e concentrador da política de crédito rural.

A hipótese orientadora da análise empreendida é que a perspectiva otimista com a qual os dados do Censo Agropecuário 2006 têm sido trabalhados desde o seu lançamento, usando a média estatística como referência, encobre e/ou negligencia a grande precariedade existente no âmbito da agricultura familiar brasileira. Argumenta-se, ainda, que a política de crédito conduzida pelo Estado, conscientemente ou não, tem contribuído para manter e até aumentar o abismo produtivo que predomina no campo. Reconhecer essa situação é estratégico tanto para ajustar o foco das políticas públicas que estão sendo operacionalizadas, como para lançar as bases de um projeto de desenvolvimento rural sustentável que avance além da modernização econômica e coloque a ampliação das capacidades das pessoas como meta prioritária.

A estrutura do texto está organizada em mais três seções além desta introdução e das considerações finais. Na segunda seção, apresenta-se a metodologia adotada pelo IBGE para elaborar as "tabulações especiais" do recenseamento estudado e classificar os diferentes tipos de estabelecimentos agropecuários do Brasil. Na terceira seção, discutem-se os principais indicadores agregados das "duas agriculturas brasileiras", expondo os motivos que justificam o seu uso por alguns atores sociais e autoridades governamentais. 
Na quarta seção, analisa-se uma série de evidências e dados no sentido de mostrar que a agricultura familiar não é um todo homogêneo, um bloco único e desenvolvido. Evidencia-se que se trata de um segmento de produtores rurais heterogêneos com uma elevada desigualdade interna, especialmente produtiva, situação cuja tendência é de manutenção e agravamento devido, entre outros fatores, a ação contraditória do Programa Nacional de Fortalecimento da Agricultura Familiar (Pronaf).

\section{Classificando os agricultores brasileiros e suas diferenças internas a partir do Censo Agropecuário 2006 ${ }^{6}$}

\subsection{Delimitação da agricultura familiar e não familiar no Brasil a partir da Lei n. 11.326/2006}

Os dados sobre os elementos da estrutura agropecuária utilizados para fundamentar a análise proposta neste artigo são provenientes do Censo Agropecuário realizado pelo IBGE em 2007, cuja data de referência foi 31 de dezembro de $2006 .^{7}$ Todavia, compete frisar que eles apresentam um caráter particular em relação a outros indicadores similares utilizados em trabalhos recentes, a exemplo dos de Leporati et al. (2014) e de Seibt et al. (2015), pois foram obtidos a partir de "tabulações especiais" da segunda apuração das estatísticas censitárias disponibilizadas para consulta pública exclusivamente no sistema eletrônico do Sidra/IBGE apenas no final de 2012.

Conforme explica o próprio IBGE (2012), com a intensificação do uso das informações da primeira apuração do Censo 2006, divulgadas em 2009, foram detec-

6. Seção elaborada, integralmente, a partir do relatório técnico-analítico desenvolvido no âmbito do Projeto de Pesquisa "Análise Multidimensional dos Dados do Novo Censo Agropecuário 2006" (AQUINO et al., 2013; SCHNEIDER e XAVIER, 2010).

7. Um novo Censo Agropecuário estava previsto para ser realizado no início de 2017 (IBGE, 2016). No entanto, a restrição orçamentária vivenciada no País levou o IBGE a adiar a coleta dos dados que só foi iniciada no final do ano passado e concluída no começo de 2018. Já a divulgação das informações obtidas, cuja data de referência é 30 de setembro de 2017, ainda não tem uma agenda definida para acontecer. tadas pelos usuários algumas divergências com relação aos dados das pesquisas agropecuárias contínuas. Assim sendo, se fez necessário proceder à revisão completa dos indicadores questionados, promovendo uma reavaliação dos procedimentos de geração de todas as variáveis, culminando na elaboração da nova base de dados referenciada, que substitui integralmente os números da primeira apuração.

O processo de elaboração das "tabulações especiais", de forma específica, envolveu um conjunto de etapas sucessivas e complementares entre si. De posse dos dados primários do levantamento, os técnicos do IBGE e do Ministério do Desenvolvimento Agrário (MDA) realizaram, inicialmente, a separação dos estabelecimentos recenseados em "Familiares" e "Não Familiares". Nessa fase, recorreu-se inteiramente à metodologia inovadora desenvolvida pela parceria entre as instituições citadas, que delimitou o universo familiar no Brasil por meio da aplicação dos critérios da Lei n. 11.326/2006 - mais conhecida como a Lei da Agricultura Familiar.

Desse modo, com base nos critérios da mencionada lei, foram considerados "Familiares" todos os produtores que (DEL GROSSI e MARQUES, 2010; IBGE, 2009; IBGE/SIDRA, 2012):

i) não detivessem estabelecimentos com área maior que quatro módulos fiscais ${ }^{8}$;

ii) utilizassem predominantemente a mão de obra da própria família nas atividades do seu estabelecimento ou empreendimento;

iii) tivessem a renda familiar predominantemente originada de atividades vinculadas ao próprio estabelecimento; e

iv) dirigissem o estabelecimento em conjunto com sua família.

Por exclusão, os estabelecimentos não enquadrados simultaneamente nos critérios descritos foram classificados como "Não Familiares". Em outros termos, eram estabelecimentos com mais de quatro módulos fiscais, tocados predominantemente por trabalhadores assalariados e dirigidos por administradores ou capatazes. Nessa perspectiva, em sintonia com estudos congêneres (FAO/INCRA, 2000; KAGEYAMA, BERGAMASCO e OLIVEIRA, 2013), os estabelecimentos agrícolas foram

8. O tamanho do módulo fiscal pode variar entre cinco e 110 hectares dependendo da sua localização no mapa do Brasil (DIEESE, 2011). 
definidos não por sua área/tamanho, mas por suas relações sociais de produção, se familiares ou do tipo patrão/empregado.

Deve-se registrar que o recorte empregado em nenhum momento buscou atribuir qualquer juízo de valor aos segmentos identificados. A ideia básica foi, fundamentalmente, agrupar os produtores com características socioeconômicas semelhantes a partir dos fundamentos legais adotados no País. Ao seguir esse procedimento, foi possível ir além dos estudos focados apenas no corte de extratos de valor da produção (ALVES e ROCHA, 2010) ou na extensão territorial das propriedades rurais (CAMPOS e NAVARRO, 2013).

É pertinente sublinhar, ainda, que o trabalho coletivo do IBGE/MDA não se resumiu apenas a delimitar os agricultores familiares no Brasil. Posteriormente à apuração dos primeiros resultados do recenseamento, também foi realizado um esforço paralelo no sentido de captar as diferenças internas do segmento, usando a legislação vigente na distribuição do crédito rural do Pronaf ${ }^{9}$ como parâmetro de estratificação.

\subsection{Tipificação da agricultura familiar segundo as normas do Pronaf em 2006/2007}

Conforme mencionado, após a identificação dos agricultores familiares o passo seguinte na construção das "tabulações especiais" foi extrair das estatísticas do Censo Agropecuário 2006 o conjunto formado pelos estabelecimentos que se enquadravam nas normas oficiais da política de crédito do Pronaf, ou seja, o público potencial do Programa. Tal procedimento viabilizou-se através de outra inovação do banco de dados criado pela parceria do IBGE com o MDA, que permitiu a inserção de variáveis derivadas nos dados censitários, possibilitando classificar os produtores familiares em "pronafianos" (Familiares Pronaf) e "não pronafianos" (Familiares não Pronaf).

Assim sendo, adotando as normas operacionais do crédito rural vigentes no Plano Safra 2006/2007 como parâmetro, foram considerados "pronafianos" apenas

9. O Programa Nacional de Fortalecimento da Agricultura Familiar (Pronaf) é a principal política pública de apoio às formas familiares de produção e trabalho existentes no campo brasileiro. Criado em 1996, o programa atua em todos os municípios do País por meio da liberação de financiamentos agropecuários em condições especiais de pagamento (AQUINO e SCHNEIDER, 2015). os estabelecimentos enquadrados na Lei n. 11.326 que: obtivessem rendimentos anuais até $\mathrm{R} \$ 80$ mil e usassem predominantemente o trabalho da família ou, no máximo, dois empregados permanentes. Estes estabelecimentos, por seu turno, foram estratificados nos cinco grupos que formavam o público potencial do Pronafem $2006^{10}$, conforme os seguintes critérios (DEL GROSSI, 2011; IBGE/SIDRA, 2012; MDA/SAF/PRONAF, 2006):

- Grupo A: Agricultores familiares assentados pelo Programa Nacional de Reforma Agrária (PNRA), beneficiários do Programa Nacional de Crédito Fundiário (PNCF) e reassentados de áreas afetadas pela construção de barragens;

- Grupo B: Agricultores familiares que obtivessem uma renda bruta anual familiar - com rebate - de até R\$3.000,00, sendo no mínimo 30\% dessa renda auferida através das atividades desenvolvidas no interior do estabelecimento agropecuário;

- Grupo C: Agricultores familiares que obtivessem uma renda bruta anual familiar - com rebate - acima de R\$3.000,00 até R\$ 16.000,00, sendo pelo menos $60 \%$ dessa renda proveniente das atividades desenvolvidas no interior do estabelecimento agropecuário;

- Grupo D: Agricultores familiares que obtivessem uma renda bruta anual familiar - com rebate - acima de $\mathrm{R} \$ 16.000,00$ até $\mathrm{R} \$$ 45.000,00, sendo pelo menos $70 \%$ desse rendimento proveniente das atividades desenvolvidas no interior do estabelecimento agropecuário, podendo, para tanto, ter até dois empregados assalariados permanentes;

- Grupo E: Agricultores familiares que obtivessem uma renda bruta anual familiar - com rebate - acima de $\mathrm{R} \$ 45.000,00$ até $\mathrm{R} \$ 80.000,00$, sendo pelo menos $80 \%$ desse rendimento proveniente das atividades desenvolvidas no interior do estabelecimento agropecuário, podendo, para tanto, ter até dois empregados assalariados permanentes.

10. De 2000 a 2008 o público potencial do Pronaf era composto pelos grupos "A", "B", “C", "D" e "E". Cada um deles, de acordo com o seu nível de renda, recebia um tratamento diferenciado no momento da concessão do crédito ofertado em condições especiais. A partir da safra 2008/2009 as regras do programa foram alteradas e os estratos " $\mathrm{C}$ ", " $\mathrm{D}$ " e "E" foram agregados em um só conjunto denominado de "Grupo Variável" (MATTEI, 2008). 
Uma vez tipificados os grupos de "pronafianos", os demais estabelecimentos familiares, com rendimentos acima de R\$ 80 mil e mais de dois empregados permanentes, foram considerados "não pronafianos" (Familiares não Pronaf). A síntese resultante dos critérios adotados pode ser visualizada no quadro a seguir, que indica ser possível aprofundar o entendimento da diversidade que existe na agropecuária brasileira por meio das "tabulações especiais" dos dados censitários corrigidos disponíveis na página eletrônica do Sidra/ IBGE (http://www.sidra.ibge.gov.br/).

Cumpre destacar que a metodologia empregada pelos técnicos do IBGE e do MDA para construir as "tabulações especiais", apesar de suas especificidades, foi inspirada nos trabalhos pioneiros do Convênio FAO/Incra (1995, 1996, 2000), que buscaram estratificar os produtores familiares conforme seu nível de renda hierarquizando-os dos mais pobres (periféricos) aos mais capitalizados (consolidados). Então, seguindo as categorias propostas pelos referidos estudos da FAO/Incra, os agricultores familiares identificados no Quadro 1 podem também ser nomeados da seguinte forma: Grupo A (assentados); Grupo B (periféricos); Grupo C (intermediários/em transição); grupos D, E e Familiar não Pronaf (consolidados).

Os novos dados obtidos através dos procedimentos mencionados foram rigorosamente corrigidos e vários outros foram atualizados em relação à publicação original do IBGE (2009), representando um "passo adiante" na construção de estatísticas sobre os variados setores que formam a agropecuária nacional. A partir deles, como poderá ser verificado nas tabelas e gráficos apresentados na continuidade do texto, será possível avançar na compreensão da grande heterogeneidade e desigualdade que marca o meio rural brasileiro no limiar do século XXI, em que os agricultores familiares extremamente pobres e pobres ainda são predominantes.

\section{Dualismo no campo, disputa por fundos públicos e a defesa da agricultura familiar homogênea e consolidada no Brasil}

O número de estabelecimentos agropecuários no Brasil apresentou expressivo crescimento do início do século XX até meados dos anos 1980. Depois de uma queda acentuada verificada na década de 1990, o indicador se estabilizou em torno de 5,2 milhões de unidades (GASQUES et al., 2010). No cenário sul-americano, segundo o levantamento realizado por Leporati et al. (2014), o País se destaca, detendo 46\% das explorações agrícolas da região. Uma parcela dessas explorações é formada pelo setor patronal, mas a maioria absoluta é tocada pelo trabalho autônomo de milhares de famílias agricultoras.

Na Tabela 1 é possível observar os dados referentes à quantidade de estabelecimentos e à área total das "duas agriculturas brasileiras", a familiar e a não familiar. Do universo de explorações recenseadas no Brasil, a agricultura familiar abrange 4.366.267 unidades, ou seja, 84,36\% do total. O segmento não familiar ou patronal registra um número significativamente menor, 809.369 estabelecimentos, englobando 15,64\% das explorações existentes.

Em relação à distribuição da posse da terra por cada tipo de produtor, a mesma tabela demonstra que a forma familiar de fazer agricultura detém apenas $24,01 \%$ da superfície total, o que lhe garante uma área média de 18 hectares. Já o segmento não familiar, embora bem menos numeroso, absorve $75,99 \%$ das

Quadro 1. Segmentação da estrutura da agropecuária brasileira na safra 2006/2007

\begin{tabular}{|c|c|c|c|}
\hline \multirow{7}{*}{$\begin{array}{l}\text { Estabelecimentos } \\
\text { agropecuários }\end{array}$} & \multicolumn{3}{|c|}{ Não Familiar } \\
\hline & \multirow{6}{*}{ Familiar (Lei n. 11.326/2006) } & \multirow{5}{*}{ Familiar Pronaf } & Grupo A \\
\hline & & & Grupo B \\
\hline & & & Grupo C \\
\hline & & & Grupo D \\
\hline & & & Grupo E \\
\hline & & \multicolumn{2}{|c|}{ Familiar não Pronaf } \\
\hline
\end{tabular}

Fonte: Aquino et al. (2013) e IBGE/Sidra (2012). 
Tabela 1. Número de estabelecimentos agropecuários, área total e média dos diferentes tipos de agricultura do Brasil - 2006

\begin{tabular}{lccccc}
\hline \multirow{2}{*}{ Tipos de agricultura } & \multicolumn{2}{c}{ Estabelecimentos } & \multicolumn{2}{c}{ Área total (ha) } & \multicolumn{2}{c}{ Área média } \\
\cline { 2 - 5 } (ha)
\end{tabular}

Fonte: Tabulação especial da 2a apuração do Censo Agropecuário 2006 (IBGE/SIDRA, 2012).

Tabela 2. Número de pessoas ocupadas nos estabelecimentos agropecuários do Brasil por tipos de agricultura - 2006

\begin{tabular}{lcc}
\hline \multicolumn{1}{c}{ Tipos de agricultura } & Pessoal ocupado & $\%$ \\
\hline Familiar & 12.323 .110 & 74,38 \\
Não familiar & 4.245 .095 & 25,62 \\
Total & 16.568 .205 & 100,00 \\
\hline
\end{tabular}

Fonte: Tabulação especial da 2ª apuração do Censo Agropecuário 2006 (IBGE/SIDRA, 2012).

terras e ocupa uma área média quase 20 vezes maior do que o setor familiar, com 313 hectares por estabelecimento, denotando a manutenção de uma estrutura agrária altamente concentrada.

Mesmo após o massivo êxodo rural verificado no Brasil, espacialmente a partir dos anos 1970, a agropecuária ainda responde pela ocupação de um contingente populacional expressivo. Em 2006, conforme consta na Tabela 2, os estabelecimentos agropecuários brasileiros abrigavam 16,6 milhões de pessoas. Entre as "duas agriculturas", a familiar responde pelas maiores quantidades de pessoas ocupadas, contabilizando 12,3 milhões, o que equivale ao percentual de $74,38 \%$ do pessoal ocupado. A agricultura não familiar, por seu turno, empregava 4,2 milhões de trabalhadores, correspondendo a $25,62 \%$ da mão de obra ocupada nos estabelecimentos rurais recenseados.

Os dados censitários confirmam, assim, o predomínio de ocupações não remuneradas ligadas ao trabalho familiar no rural brasileiro. Ou seja, o avanço capitalista não levou à predominância absoluta do assalariamento. Ademais, a ampliação do grau de cobertura das políticas públicas nas áreas rurais gerou certa estabilidade de renda para a agricultura familiar e ampliou sua capacidade de reter mão de obra, mesmo que em condições mínimas de reprodução econômica (BUAINAIN e DEDECCA, 2010; HELFAND, SOARES e PEREIRA, 2014).

Quanto ao papel das "duas agriculturas" na geração de riqueza agropecuária, medido em termos de
Valor Bruto da Produção (VBP) ${ }^{11}$, percebe-se que há uma grande distância entre os produtores. De maneira agregada, a Tabela 3 evidencia que a agricultura familiar gera um VBP correspondente a 33,23\% da riqueza produzida nas explorações agrícolas brasileiras, em torno de $1 / 3$ da mesma. ${ }^{12}$ Os estabelecimentos não familiares, que dispõem de extensões maiores de terra e geralmente empregam tecnologias modernas de produção, foram responsáveis por $2 / 3$ da riqueza adicionada $(66,77 \%)$, atingindo a cifra de $\mathrm{R} \$ 109,5$ bilhões.

Nota-se, porém, que a participação da agricultura familiar no VBP é superior ao percentual da área que a mesma ocupa (24\%) e, em termos de geração de riqueza por hectare, o setor se mostra bem mais eficiente do que o segmento patronal. Além disso, vários estudos ressaltam que ela produz boa parte dos alimentos básicos que compõem a dieta da população brasileira, enquanto as explorações patronais se concentram principalmente na produção de mercadorias para exportação (ANANIAS, 2015; FERNANDES, 2014;

11. O Valor Bruto da Produção (VBP) foi calculado a partir da soma de três indicadores (IBGE, 2009): valor da produção vegetal, valor da produção animal e valor agregado da agroindústria (que é igual ao valor total dos produtos processados menos o valor das matérias-primas utilizadas).

12. Apesar da correção tabular realizada pelo IBGE, algumas análises ainda insistem em utilizar os dados desatualizados da primeira apuração do Censo Agropecuário 2006. Por exemplo, Ananias (2015) e Seibt et al. (2015) citam que a participação da agricultura familiar no VBP é de $38 \%$, quando o valor correto obtido por meio dos cálculos da segunda apuração é 33\%. 
Tabela 3. Participação da agricultura familiar e não familiar no Valor Bruto da Produção (VBP) da agropecuária brasileira - 2006

\begin{tabular}{ccc}
\hline Tipos de agricultura & VBP $(\mathbf{R} \$ \mathbf{1 , 0 0})$ & $\%$ \\
\hline Familiar & 54.494 .117 .490 & 33,23 \\
Não familiar & 109.492 .176 .940 & 66,77 \\
Total & 163.986 .294 .428 & 100,00 \\
\hline
\end{tabular}

Fonte: Tabulação especial da 2ª apuração do Censo Agropecuário 2006 (IBGE/SIDRA, 2012).

FRANÇA, DEL GROSSI e MARQUES, 2009; SAF/MDA, 2015; SEIBT et al., 2015). ${ }^{13}$

Os indicadores apresentados têm sido utilizados, com frequência, como uma espécie de "munição" na guerra de números travada entre os defensores de cada categoria de produtores. Por um lado, uma corrente enfatiza que a agricultura familiar é mais numerosa, gera mais emprego e produz um percentual expressivo da riqueza em menor área. Por outro lado, os membros da bancada ruralista argumentam que o setor não familiar gera menos emprego, mas é mais dinâmico e contribui para o superávit da balança comercial do País (BRUNO, 2014). Esse embate é explicitado, como bem lembra Graziano da Silva (2009, 2010), nas disputas entre ministérios (MDA x Mapa) e organizações de classe (Contag/Fetraf $x$ CNA).

De fato, a Figura 1 indica que o MDA usava as estatísticas censitárias, baseadas sempre nas médias das grandes variáveis da agricultura familiar (número de estabelecimentos, VBP ou PIB e percentual de postos de trabalho gerados), para afirmar o peso e a importância do segmento e garantir sua justa legitimidade social frente à sociedade brasileira. Do mesmo modo, segundo Picolotto $(2012,2014)$, os dados médios do Censo Agropecuário 2006 do IBGE também são utilizados de forma otimista por outros atores como os movimentos sociais do campo, o sindicalismo rural, ONG's e demais organizações ligadas à agricultura familiar brasileira, para justificar suas lutas e garantir um lugar na agenda de prioridades do Estado.

13. Diferentes representantes dos movimentos sociais do campo e autoridades governamentais têm repetido que a agricultura familiar é responsável pela produção de $70 \%$ dos alimentos consumidos pela população brasileira. Hoffmann (2014), contudo, ressalta que a categoria se destaca realmente na produção de muitos produtos voltados ao abastecimento do mercado doméstico, mas esse percentual agregado é superestimado e não pode ser generalizado.
Figura 1. Marketing dos indicadores médios da agricultura familiar brasileira

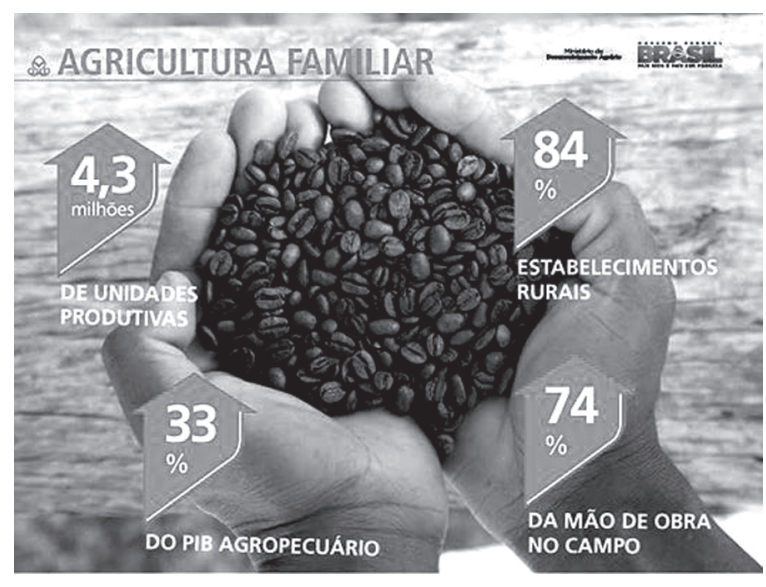

Fonte: MDA (2014).

Os esforços para defender a agricultura familiar são justificáveis por vários motivos. Isso porque, apesar de sua relevância, o setor ainda ocupa um lugar secundário na política agrícola nacional e, o que é mais grave, tem perdido espaço recentemente. A Figura 2 revela que a participação percentual da agricultura familiar na distribuição do crédito rural alcançou $17 \%$ nos anos 20052009, declinando para o patamar de $13 \%$ nas últimas safras (2013-16). O perfil distributivo apresentado reflete o movimento organizado do chamado "agronegócio" no sentido de captar fatias crescentes de recursos do crédito rural, mas também evidencia a desigualdade que o próprio Estado introduz nos processos de reprodução socioeconômicos das "duas agriculturas" analisadas, com um nítido desfavorecimento das formas familiares de produção e trabalho no campo.

Tal quadro associa-se à opção deliberada do governo brasileiro nos anos recentes pela agricultura empresarial de larga escala, constituindo o que Delgado (2012) tem chamado de "pacto em torno do agronegócio", haja vista que o modelo de desenvolvimento dependente adotado precisa deste setor social para o crescimento 
Figura 2. Distribuição dos recursos programados do crédito rural por tipos de agricultura no Brasil Safras 2003/2004 a 2015/2016 (em \%)

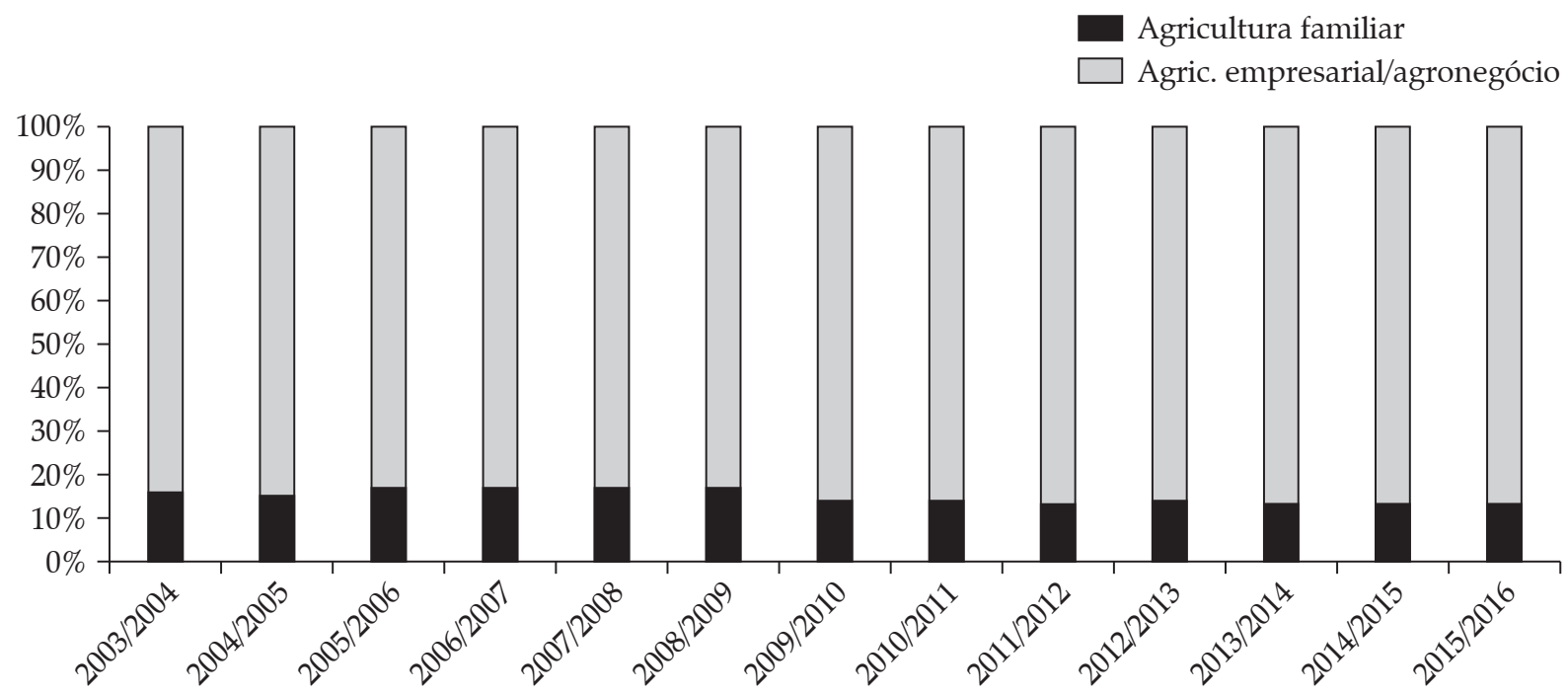

Nota: Dados organizados a partir de Bianchini (2015).

Fonte: SAF/MDA e Mapa (Planos Safra da Agricultura Familiar e da Agricultura Empresarial, 2003/04 a 2015/16).

do PIB, especialmente via exportação de produtos primários e commodities, mesmo admitindo suas contradições socioambientais, como a concentração de renda, a superexploração do trabalho e dos recursos naturais.

Para tentar contrabalançar o movimento concentrador da política agrícola, os defensores da ala desenvolvimentista da sociedade (movimentos sociais do campo e autoridades governamentais ligadas ao extinto MDA) intensificam o debate e o seu foco principal tem se voltado para exaltar as qualidades da agricultura familiar a partir dos dados agregados das estatísticas censitárias sumariadas na Figura 1, não raro apresentando a referida categoria como um bloco de produtores coeso e consolidado. Entre os argumentos utilizados, ganha relevo o aspecto econômico e modernizador do segmento quase sempre tentando reagir ao discurso das entidades que representam os grandes produtores agrícolas empresariais. Em termos práticos, embora essa postura política seja legítima, é forçoso admitir que ela tem contribuído para alimentar um dualismo maniqueísta limitado analiticamente.

Nesse contexto, não restam dúvidas sobre a importância e as potencialidades da agricultura familiar brasileira. Porém, é preciso ir além das noções generalizantes e demonstrar que o problema das desigualdades do campo não limitam-se apenas à polarização familiar versus não familiar. Na verdade, compete esclarecer que a própria agricultura familiar nacional é marcada por flagrantes disparidades socioeconômicas internas, geralmente ocultadas pelos indicadores médios do Censo Agropecuário 2006. Do mesmo modo, a disputa por fundos públicos também se manifesta no âmbito do setor, onde se verifica o privilegiamento dos grupos capitalizados e a marginalização da fração mais pobre do acesso a melhores condições produtivas.

\section{Além da visão generalizante: heterogeneidade e desigualdades internas na agricultura familiar brasileira $^{14}$}

A visão generalizante que vem sendo difundida por alguns defensores da agricultura familiar no Brasil, construída a partir da média dos indicadores estatís-

14. Embora o foco do presente artigo seja o estudo da agricultura familiar, é importante destacar que a diversidade e a desigualdade produtiva também se manifestam no âmbito do segmento agrícola empresarial não familiar ou agronegócio, o qual apresenta uma expressiva heterogeneidade político-econômica e não pode ser tratado analiticamente como um bloco unitário (CAMARGO e OLIVEIRA, 2011). 
ticos e que encara o segmento como um "ser único e homogêneo", possui frágil sustentação empírica. Com efeito, pode-se afirmar que existem "várias agriculturas familiares" no campo brasileiro, conforme sugere uma vasta gama de estudos (BELIK, 2015; COUTO, 2014; FAO/INCRA, 2000; KAGEYAMA, BERGAMASCO e OLIVEIRA, 2013; LAMARCHE, 1993; NEVES, 2007; SCHNEIDER e CASSOL, 2014, entre outros). Esta realidade pode ser captada parcialmente pela tipologia adotada para delimitar o público do Pronaf, esboçada na subseção 2.2, embora seu uso ainda seja restrito até mesmo entre os técnicos do MDA que contribuíram para sua elaboração.

De acordo com a Tabela 4, preparada a partir da referida metodologia, do total de agricultores familiares brasileiros, 2,4 milhões ou 55,34\% do total estavam incluídos dentro do Grupo B, formado pelo público extremamente pobre da categoria. Os agricultores dos grupos A e C, representados pelos assentados da reforma agrária e pela faixa pobre/intermediária, englobavam 1,3 milhão de estabelecimentos (30,15\% do total). De outro lado, a fração constituída pelos agricultores familiares consolidados (grupos D, E e Familiar não Pronaf), abrangiam pouco mais de 630 mil explorações, alcançando 14,51\% do universo familiar do País.

Os dados analisados evidenciam, portanto, que a maioria absoluta da agricultura familiar brasileira é formada por produtores extremamente pobres ou pobres/ intermediários. O setor consolidado, detentor de maiores rendas, representa somente uma pequena parcela da categoria. Tais informações ratificam as observações anteriores de que o uso da média dos indicadores agregados do IBGE esconde grandes discrepâncias. Ou seja, do ponto de vista explicativo ela encobre uma multiplicidade de situações que caracterizam o cenário agrário nacional. Essa limitação, porém, é parcialmente contornada pelas "tabulações especiais" das estatísticas censitárias, que permitem melhor escalonamento e diferenciação no interior do conjunto de explorações familiares.

Nota-se que a distribuição espacial dos diferentes tipos de agricultores familiares apresenta peculiaridades regionais marcantes. Neste aspecto, a Tabela 5 indica que o Grupo A estava mais presente na região Nordeste, com 212.091 estabelecimentos ou 39,76\% do total, seguida pelas regiões Norte $(26,52 \%)$, CentroOeste $(15,12 \%)$, Sul $(11,43 \%)$ e Sudeste $(7,17 \%)$.

Tabela 4. Número de estabelecimentos dos distintos grupos de agricultores familiares do Brasil - 2006

\begin{tabular}{ccc}
\hline Grupos de agricultores familiares & Estabelecimentos & $\%$ \\
\hline A & 533.454 & 12,22 \\
B & 2.416 .127 & 55,34 \\
C & 782.982 & 17,93 \\
D & 287.464 & 6,58 \\
E & 62.899 & 1,44 \\
Familiar não Pronaf & 283.341 & 6,49 \\
Total familiar & 4.366 .267 & 100,00 \\
\hline
\end{tabular}

Fonte: Tabulação especial da 2ª apuração do Censo Agropecuário 2006 (IBGE/SIDRA, 2012).

Tabela 5. Distribuição dos estabelecimentos dos distintos grupos de agricultores familiares segundo as regiões do Brasil - 2006

\begin{tabular}{|c|c|c|c|c|c|c|c|c|c|c|c|c|}
\hline \multirow{2}{*}{ Regiões } & \multicolumn{2}{|c|}{ Grupo A } & \multicolumn{2}{|c|}{ Grupo B } & \multicolumn{2}{|c|}{ Grupo C } & \multicolumn{2}{|c|}{ Grupo D } & \multicolumn{2}{|c|}{ Grupo E } & \multicolumn{2}{|c|}{$\begin{array}{c}\text { Familiar Não } \\
\text { PRONAF }\end{array}$} \\
\hline & Total & $\%$ & Total & $\%$ & Total & $\%$ & Total & $\%$ & Total & $\%$ & Total & $\%$ \\
\hline Norte & 141.482 & 26,52 & 154.318 & 6,39 & 79.716 & 10,18 & 16.315 & 5,68 & 3.841 & 6,11 & 16.994 & 6,00 \\
\hline Nordeste & 212.091 & 39,76 & 1.567 .863 & 64,89 & 238.209 & 30,42 & 45.698 & 15,90 & 11.072 & 17,6 & 112.198 & 39,60 \\
\hline Sudeste & 38.238 & 7,17 & 356.526 & 14,76 & 160.803 & 20,54 & 59.705 & 20,77 & 14.452 & 22,98 & 70.031 & 24,72 \\
\hline Sul & 60.982 & 11,43 & 269.668 & 11,16 & 266.742 & 34,07 & 154.223 & 53,65 & 31.070 & 49,4 & 67.008 & 23,65 \\
\hline C.-Oeste & 80.661 & 15,12 & 67.752 & 2,80 & 37.512 & 4,79 & 11.523 & 4,01 & 2.464 & 3,92 & 17.110 & 6,04 \\
\hline Brasil & 533.454 & 100,00 & 2.416 .127 & 100,00 & 782.982 & 100,00 & 287.464 & 100,00 & 62.899 & 100,00 & 283.341 & 100,00 \\
\hline
\end{tabular}

Fonte: Tabulação especial da 2a apuração do Censo Agropecuário 2006 (IBGE/SIDRA, 2012). 
De maneira semelhante aos agricultores assentados em projetos de reforma agrária, o Grupo B também era mais comum na região Nordeste do Brasil. Somente nessa porção do território brasileiro foram identificados 1.567.863 estabelecimentos classificados nessa categoria de produtores de baixa renda, ou seja, $64,89 \%$ do total nacional. As demais regiões, somadas, abarcavam apenas $35,11 \%$ desse grupo formado pelos mais pobres entre os agricultores familiares, com rendimentos inferiores a R 3 mil por ano.

A distribuição geográfica dos produtores estudados começa a mudar, contudo, a partir do momento que se observa a localização dos agricultores que apresentam maiores níveis de renda bruta anual familiar. Ainda na Tabela 5 percebe-se que o Grupo C apresentava uma frequência maior na região Sul, abrangendo 266.742 estabelecimentos ou $34,07 \%$ do total de agricultores incluídos nessa classificação. Os demais estavam dispersos pelas regiões Nordeste $(30,42 \%)$, Sudeste $(20,54 \%)$, Norte $(10,18 \%)$ e Centro-Oeste $(4,79 \%)$.

Os grupos D e E, por sua vez, estão concentrados majoritariamente nas regióes Sul e Sudeste, que juntas abarcam mais de $70 \%$ de ambas as categorias e aproximadamente 50\% do setor Familiar não Pronaf. Entretanto, vale destacar que uma parcela importante da fração mais consolidada da categoria também registra presença no Nordeste, que detém algo em torno de $40 \%$ dos "não pronafianos", muito provavelmente localizados nas áreas dos perímetros irrigados e em outras manchas de modernização regional, a exemplo do oeste da Bahia e do sul dos estados do Maranhão e do Piauí.

Em termos demográficos, do total de 12,3 milhões de pessoas abrigadas nos estabelecimentos familiares do Brasil em 2006, metade (50,39\%) estava ocupada nas pequenas propriedades dos produtores periféricos do
Pronaf. Os grupos A e C detinham, respectivamente, $13,04 \%$ e $19,21 \%$ do pessoal ocupado nos estabelecimentos. O restante do contingente populacional estava situado nos sítios mais estruturados economicamente pertencentes aos tipos D, E e "não pronafianos", representando 17,35\% das ocupações (Tabela 6).

Os números destacados sinalizam que a afirmação generalista de que a agricultura familiar gera $74 \%$ dos postos de trabalho do campo exposta na Figura 1 deve ser relativizada. Isso porque a maior parte das pessoas envolvidas na atividade vive e trabalha em estabelecimentos agropecuários de baixíssima renda ou em explorações pobres/intermediárias, o que não abre espaço para qualquer ufanismo exagerado, já que suas condições produtivas são extremamente precárias em quase todas as regiões do País (AQUINO et al., 2013; DELGADO, 2005; GUANZIROLI, BUAINAIN e DI SABBATO, 2012).

A desigualdade produtiva no setor familiar do Brasil se expressa de forma mais concreta quando se observa a participação de cada tipo de produtor no VBP, bem como na sua capacidade de gerar riqueza agropecuária individualmente.

A Tabela 7 revela que as disparidades econômicas entre os grupos são gritantes. Em um extremo, destacam-se os 2,03 milhões de estabelecimentos familiares do Grupo B que declararam alguma produção agropecuária em 2006, os quais, apesar de sua representatividade numérica, geraram apenas o valor de R\$ 2,8 bilhões (5,19\% do total), alcançando a média de $\mathrm{R} \$ 1.389,00$ por unidade e algo em torno de $4 \mathrm{SM} /$ ano.

Os familiares classificados nos grupos A e C do Pronaf figuram em uma faixa intermediária, respondendo por $26 \%$ da riqueza obtida pelo setor e apresentam valores médios de produção bastante aproximados. A sua capacidade de gerar riqueza agrícola oscila entre

Tabela 6. Número de pessoas ocupadas nos estabelecimentos da agricultura familiar do Brasil - 2006

\begin{tabular}{ccc}
\hline Grupos de Agricultores Familiares & Pessoal Ocupado & $\%$ \\
\hline A & 1.607 .324 & 13,04 \\
B & 6.209 .544 & 50,39 \\
C & 2.367 .483 & 19,21 \\
D & 962.636 & 7,81 \\
E & 227.063 & 1,84 \\
Familiar não Pronaf & 949.060 & 7,70 \\
Total familiar & 12.323 .110 & 100,00 \\
\hline
\end{tabular}

Fonte: Tabulação especial da 2ª apuração do Censo Agropecuário 2006 (IBGE/SIDRA, 2012). 
Tabela 7. Participação dos distintos grupos no Valor Bruto da Produção (VBP) da agricultura familiar brasileira 2006 (Em R\$1,00)

\begin{tabular}{|c|c|c|c|c|c|c|}
\hline $\begin{array}{l}\text { Grupos de } \\
\text { agricultores familiares }\end{array}$ & $\begin{array}{l}\text { Estabelecimentos } \\
\text { "com" VBP } \\
\text { (A) }\end{array}$ & $\%$ & $\begin{array}{l}\text { Valor bruto da } \\
\text { produção } \\
\text { (B) }\end{array}$ & $\%$ & $\begin{array}{l}\text { VBP médio } \\
\text { (B/A) }\end{array}$ & $\begin{array}{l}\text { VBP médio } \\
\text { (SM/Ano)* }^{*}\end{array}$ \\
\hline A & 462.971 & 11,86 & 5.711 .549 .031 & 10,48 & 12.337 & 35 \\
\hline B & 2.035 .749 & 52,16 & 2.827.925.065 & 5,19 & 1.389 & 4 \\
\hline $\mathrm{C}$ & 781.616 & 20,03 & 8.460 .026 .343 & 15,52 & 10.824 & 31 \\
\hline $\mathrm{D}$ & 287.211 & 7,36 & 10.593.823.381 & 19,44 & 36.885 & 105 \\
\hline $\mathrm{E}$ & 62.827 & 1,61 & 4.874.183.586 & 8,94 & 77.581 & 222 \\
\hline Familiar não Pronaf & 272.308 & 6,98 & 22.026 .610 .084 & 40,42 & 80.889 & 231 \\
\hline Total familiar & 3.902 .682 & 100,00 & 54.494.117.490 & 100,00 & 13.963 & 40 \\
\hline
\end{tabular}

* SM/Ano = Salário Mínimo ao ano, cujo valor vigente em 2006 era de R\$ 350,00.

Fonte: Tabulação especial da 2ª apuração do Censo Agropecuário 2006 (IBGE/SIDRA, 2012).

R\$ 10 e 12 mil, o que garante um montante que varia de 31 a $35 \mathrm{SM} /$ ano por exploração.

No extremo oposto da distribuição, aparecerem os segmentos consolidados (D, E e Familiar não Pronaf), representados por apenas $16 \%$ da unidades, sendo responsáveis por aproximadamente $70 \%$ da produção do setor e pelos maiores níveis de valor obtidos por unidade produtiva (de 105 a 231 SM/ano), constituindo a "elite" da agricultura familiar nacional.

Os indicadores elencados aqui corroboram os resultados da pesquisa de Guanziroli, Buainain e Di Sabbato (2012), bem como os de outros trabalhos que ressaltam a situação de precariedade vivenciada pela maioria dos agricultores familiares brasileiros (AQUINO et al., 2013; DELGADO, 2005; LEPORATI et al., 2014). Por outro lado, evidenciam a concentração econômica e o abismo produtivo prevalecente no âmbito do setor, algo que tem sido encoberto pela cortina de fumaça criada no meio da guerra de números travada a partir do dualismo maniqueísta em voga no País.

Recentemente, tem se argumentado que ocorreu uma evolução positiva e que o quadro de desigualdade teria mudado completamente nas áreas rurais do Brasil. A justificativa para isso seria o inédito crescimento da chamada "nova classe média rural" e a substancial melhoria dos padrões de consumo no campo na última década (ANANIAS, 2015; MDA, 2016; NERI, MELO e MONTE, 2012; SAF/MDA, 2015). ${ }^{15}$ É impor-

15. Estimativas oficiais apontam que, entre 2003 e 2013, “a renda da agricultura familiar cresceu $52 \%$, o que permitiu que mais de 3,7 milhões de pessoas ascendessem para a classe média" (MDA/SAF/PRONAF, 2013, p. 5). tante admitir que a distribuição de renda avançou e os níveis de qualidade de vida se elevaram no meio rural. Mas uma análise dos dados atuais do público do Pronaf mostra que do ponto de vista das condições materiais de produção não aconteceram mudanças significativas. Na verdade, verifica-se a manutenção de uma elevada desigualdade econômica no interior da categoria.

Segundo a Tabela 8, é possível notar que os segmentos extremamente pobres e de baixa renda da agricultura familiar, situados na base da pirâmide social do campo (Classes D e E), ainda são predominantes no território nacional. Conjuntamente, eles representam $70 \%$ dos agricultores potencialmente enquadráveis no Pronaf e respondem por apenas $16 \%$ da produção do segmento. A chamada Classe C (ou classe média rural) abrange pouco mais de $20 \%$ dos estabelecimentos e gera 1/3 do VBP. Já a "elite" da agricultura familiar, formada pelos produtores com renda acima de $\mathrm{R} \$ 100 \mathrm{mil}$ (Classes A e B), correspondem apenas a 8\% do total, mas geram mais da metade do valor da produção do segmento (51\%).

A partir da mesma base de dados, constata-se que o abismo produtivo se mantém em todas as regiões brasileiras, apresentando, inclusive, sinais de piora relativamente aos números do levantamento censitário do IBGE de 2006. De acordo com os percentuais da Figura 3, a agricultura familiar das regiões Norte e Nordeste é formada basicamente por agricultores extremamente pobres e de baixa renda. A Classe $C$ se destaca no Norte, Sudeste e Centro-Oeste, abrangendo metade dos agricultores familiares do Sul. Os segmentos de maiores rendas praticamente não aprecem no Norte e no Nordeste, sendo mais frequentes no âmbito 
Tabela 8. Distribuição dos agricultores familiares com Declaração de Aptidão ao Pronaf (DAP) segundo faixas de Valor Bruto da Produção (VBP) anual (Em R\$ de dez./2014)

\begin{tabular}{lccc}
\hline \multicolumn{1}{c}{ Faixas de VBP (R\$ 1,00)* } & No de agricultores familiares & \% & \% VBP \\
\hline Até 9.240 (Classe E) & 2.300 .862 & 44,9 & 5,1 \\
De 9.240 a 28.368 (Classe D) & 1.260 .477 & 24,6 & 11,2 \\
De 28.368 a 103.680 (Classe C) & 1.142 .169 & 22,3 & 32,7 \\
Acima de 103.680 (Classes A/B) & 422.963 & 8,3 & 51,0 \\
Total Familiar c/ DAP & 5.126 .471 & 100,00 & 100,0 \\
\hline
\end{tabular}

* A nomenclatura das classes de renda exposta na tabela é o inverso da categorização do público potencial do Pronaf, sendo as classes D e E as mais pobres, a Classe $\mathrm{C}$ formada pelo segmento intermediário e as classes $\mathrm{A} / \mathrm{B}$ representadas pelo grupo de agricultores familiares localizados no topo da pirâmide social da categoria.

Fonte: SAF/MDA (2015, p. 9).

da agricultura familiar do Centro-Oeste, do Sudeste e, principalmente, do Sul.

Diante do exposto, depreende-se que a agricultura familiar brasileira continua marcada por uma significativa desigualdade socioespacial, fundamentada, entre outros fatores, nos largos desníveis de renda entres os produtores que habitam as distintas regiões do Brasil. Ademais, as diferenças internas prevalecentes no interior do segmento indicam claramente a manutenção da situação revelada por meio das "tabulações especiais" do Censo Agropecuário 2006, em que os contingentes populacionais mais expressivos ainda são privados dos meios produtivos necessários para avançar em direção aos patamares de renda mais elevados.

É possível encontrar na literatura especializada muitas explicações para o quadro de desigualdade predominante entre os agricultores familiares brasileiros. Entre essas explicações se destacam aspectos relevantes, como, por exemplo: a herança histórica excludente do modelo agrícola adotado no País desde a colonização (ARAÚJO, 1997; DELGADO, 2005; WANDERLEY, 2014), a elevada concentração fundiária (HOFFMANN e NEY, 2010; LAMARCHE, 1993), o arrefecimento recente da reforma agrária (ESQUERDO e BERGAMASCO, 2013), o baixo padrão tecnológico dos pequenos estabelecimentos (ALVES e CONTINI, 2013), a precariedade do quadro educacional dos produtores pobres (HELFAND e PEREIRA, 2012), a pequena abrangência dos programas de assistência técnica e de comercialização (AQUINO et al., 2013; BELIK, 2015), a baixa sinergia das políticas de desenvolvimento rural com as políticas sociais (GARCIA, HELFAND e SOUZA, 2016), entre outros. Adicionalmente, cumpre destacar que a política agrícola patrocinada pelo Estado tem desempenhado um papel decisivo para a manutenção do cenário apresentado por meio do privilegiamento

Figura 3. Distribuição do número de agricultores familiares com DAP segundo grandes regiões e por faixa de VBP anual - dez./2014 (em \%)

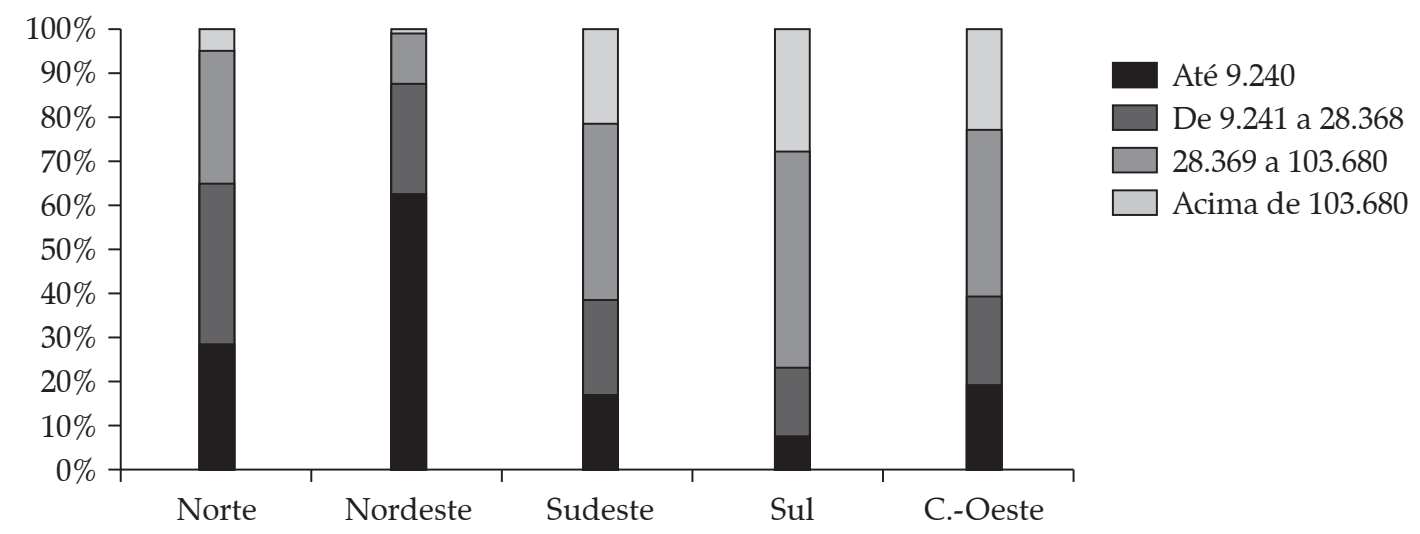

Fonte: SAF/MDA (2015, p. 10). 
dos grupos mais capitalizados na distribuição do crédito do Pronaf.

A esse respeito, a Figura 4 mostra dois movimentos bem distintos. Primeiro, os agricultores familiares mais pobres (grupos A e B) que lograram deter até $20 \%$ dos recursos do crédito rural, a partir de 2003 foram diminuindo a sua participação na tomada dos financiamentos públicos, chegando a 2011 com pouco mais de $10 \%$ dos montantes aplicados. O segundo movimento é o de crescimento e de concentração dos recursos do Pronaf em favor dos segmentos familiares intermediários e mais capitalizados do rural brasileiro, albergados no chamado Grupo Variável. Estes agricultores obtinham, juntos, em torno de $80 \%$ dos recursos do Programa no início da série, saltando depois de 2008 para algo em torno de $85-87 \%$ dos valores aplicados e chegando perto de $90 \%$ dos mesmos nos anos recentes (2008 e 2011).

Os percentuais referenciados evidenciam que a política de crédito rural atualmente vigente, ao invés de diminuir, está acirrando a concentração e a desigualdade produtiva entre os produtores familiares. Tal processo vem ganhando intensidade inédita desde 2008 com o advento do Pronaf Mais Alimentos, linha do Programa criada para estimular a modernização tecnológica da categoria via financiamento de máquinas e equipamentos, o qual tem concentrado seus investimentos nos estabelecimentos familiares consolidados do Sul e do Sudeste. Por outro lado, a parcela majoritária do segmento, constituída pelos assentados da reforma agrária e pelos agricultores periféricos localizados principalmente nas regiões Norte e Nordeste, tem sido marginalizada na distribuição dos ativos produtivos, tornando-se dependente de outras fontes de renda de fora da propriedade e das transferências sociais para sobreviver (AQUINO e SCHNEIDER, 2015; BELIK, 2014; COUTO, 2014; GAZOLLA e SCHNEIDER, 2013).

Percebe-se, então, que as contradições da política de crédito rural no Brasil não se resumem à polarização entre as "duas agriculturas brasileiras". Dentro do setor familiar há um claro favorecimento dos grupos com maiores patamares de renda em detrimento dos mais pobres, que se constituem nos verdadeiros marginalizados do campo. Parte desse problema advém do modelo de distribuição do crédito do Pronaf desde sua origem, em 1996, que elege como público a ser incentivado as categorias com potencial de modernização e não o setor periférico. Outra parte está associada ao lobby dos produtores do Sul e do Sudeste, bem como a ação do MDA, que no afã de garantir a representação dos produtores mais estruturados frente ao MAPA/CNA, abriu as portas do programa para os setores mais capitalizados (AQUINO e SCHNEIDER, 2015;

Figura 4. Participação dos grupos de agricultores familiares na distribuição do montante de crédito rural do Pronaf no período de 1999 a 2011 (em \%)

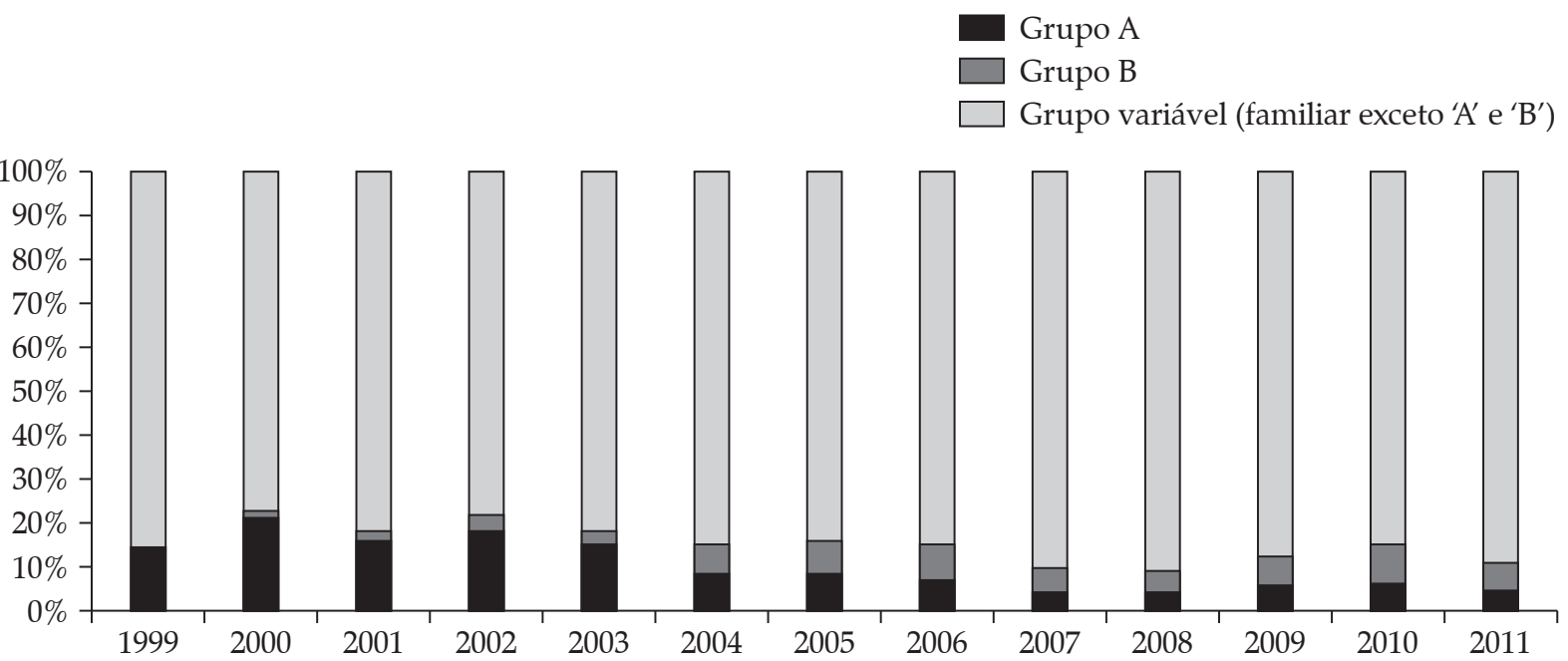

Nota: Dados organizados por Aquino e Schneider (2015).

Fonte: SAF/MDA (2013). 
PICOLOTTO, 2012). O resultado final desse processo é a constituição de uma "geração de agricultores desigualmente equipados", ou seja, uma minoria com os ativos necessários para produzir e a maioria bloqueada por "múltiplas carências produtivas" (AQUINO et al., 2013; BELIK, 2015; COUTO, DUFUMIER e REIS, 2013).

Dessa forma, ao eleger a assim chamada classe média familiar como segmento preferencial e relegar os grupos mais pobres às políticas sociais e de inclusão administradas pelo Ministério do Desenvolvimento Social (MDS), o Estado brasileiro parece caminhar na contramão da proposta de apoiar preferencialmente os setores marginalizados do campo. Naturalmente, essa situação pode ser alterada pela construção de um novo pacto social. Mas, para isso, será necessário mudar o foco da ação para os grupos A e B, os quais concentram $2 / 3$ do pessoal ocupado na agricultura familiar e em nenhum momento da história recente do Brasil foram encarados como prioridade da ação governamental. Tal mudança, contudo, dificilmente acontecerá enquanto os defensores da agricultura familiar não perceberem que a questão agrária brasileira vai além do dualismo maniqueísta pautado em médias da realidade social e voltarem suas atenções para os limites e desafios das políticas implementadas para o setor nas últimas décadas.

\section{Considerações finais}

A agricultura familiar brasileira tem peso importante na estrutura agrária nacional, além de ser responsável pela geração de empregos, ocupações, renda e pela produção de alimentos destinados ao mercado doméstico. Reconhecer seus múltiplos papeis no desenvolvimento rural é uma tarefa fundamental. Entretanto, a forma como alguns atores sociais, acadêmicos e autoridades governamentais vêm utilizando os dados estatísticos, especialmente os do último censo agropecuário realizado pelo IBGE até 2015, não tem contribuído para avançar na compreensão das especificidades do segmento. A utilização acrítica dos indicadores censitários, na constante disputa por reconhecimento social e fundos públicos, tem gerado dentro e fora do País uma visão generalizante de uma agricultura familiar brasileira homogênea e inteiramente consolidada que não existe na realidade concreta.
Neste artigo procuramos ressaltar a necessidade de ir além da média estatística nos estudos sobre as formas familiares de produção, visando demonstrar suas características socioeconômicas e produtivas em nível geral, mas também nas diferentes regiões, agroecossistemas e realidades em que essa forma de produção e trabalho se encontra presente. Embora possa parecer simples, tal proposição apresenta-se como um grande desafio. Isso porque atualmente observa-se uma expressiva exacerbação política e acadêmica em torno da dualidade envolvendo as "duas agriculturas brasileiras" (familiar versus não familiar/agronegócio), o que tem obscurecido e encoberto o elevado quadro de desigualdade e concentração econômica que caracteriza o setor.

A partir das "tabulações especiais" do Censo Agropecuário 2006, o estudo evidenciou que a situação da maioria absoluta dos agricultores familiares brasileiros é extremamente precária. Mais da metade dos estabelecimentos da categoria estão albergados no chamado Grupo B do Pronaf, um segmento extremamente pobre que produz muito pouco e depende da ajuda do governo para permanecer no campo. Outra parte significativa é formada por produtores pobres e intermediários (grupos A e B), que, embora apresentem melhores condições produtivas do que a parcela anterior, também reúnem chances limitadas de prosperidade sem o apoio estatal. Já a parcela consolidada da categoria, grupos D, E e "não pronafianos", é representada por menos de um quinto dos estabelecimentos, mas produz 70\% do VBP criado nas referidas propriedades.

Os dados analisados corroboram os resultados de outras pesquisadas realizadas sobre o tema. Ademais, estão em sintonia com levantamentos recentes que indicam que o grosso da agricultura familiar brasileira permanece situada nos degraus mais baixos da pirâmide social do campo, especialmente nas regióes Norte e Nordeste. A chamada classe média rural, asim como o seleto grupo de produtores que apresentam semelhança com o family farming americano, ainda são um fenômeno limitado e restrito às áreas mais dinâmicas do território nacional.

Com efeito, existem várias explicações para o quadro apresentado. Contudo, as evidências reunidas ao longo da análise sugerem que uma das causas principais da situação retratada está associada às contradições da intervenção estatal via política de crédito rural. De um lado, nota-se uma ampliação dos recursos programados 
para a agricultura empresarial, que tem expandido sua participação na divisão dos fundos públicos relativamente ao universo familiar. Do outro lado, percebe-se um claro direcionamento da política de crédito do Pronaf para os segmentos intermediários e consolidados da categoria em detrimento do segmento periférico, contribuindo para manter e até aumentar o abismo produtivo que predomina no campo.

Nesses termos, a política governamental de crédito rural que, em tese, deveria funcionar como um instrumento equalizador das desigualdades, parece estar desempenhando efeito contrário, ao aumentar e cristalizar a concentração produtiva no meio rural. No caso da agricultura familiar, contribuiu para isso a estratégia do próprio MDA de intensificar a modernização tecnológica de uma parcela do setor, por meio do Pronaf Mais Alimentos, deixando a maioria do segmento dependente das políticas administradas pelo MDS para sobreviver. Isso significa que, inconscientemente ou não, o governo brasileiro está seguindo o receituário conservador que coloca a tecnologia como caminho único para o progresso social. Logo, ao contrário do que se imagina a partir das visões generalistas da realidade agrária, percebe-se que a luta contra a pobreza estrutural e a desigualdade produtiva no campo continua distante do seu capítulo final, uma vez que a perspectiva modernizante adotada até recentemente é limitada e a mudança social exige um amplo projeto de desenvolvimento rural ainda inexistente em nosso País.

\section{Referências}

ABRAMOVAY, R. Paradigmas do capitalismo agrário em questão. Campinas: Hucitec, 1992.

ALVES, E. e ROCHA, D. P. Ganhar tempo é possível? In: GASQUES, J. G., VIEIRA FILHO, J. E. e NAVARRO, Z. (Orgs.). A agricultura brasileira: desempenho, desafios e perspectivas. Brasília: IPEA, 2010. p. 275-290.

ALVES, E. e CONTINI, E. Tecnologia: prosperidade e pobreza nos campos. In: SERRA, N. C. (Coord.). O Censo entra em campo: o IBGE e a história dos recenseamentos agropecuários. Rio de Janeiro: IBGE, 2014. p. 205-229.

ANANIAS, P. Uma agenda democrática para o Brasil rural. [S.1.]: Fundação Perseu Abramo, 2015. (Ciclo de Debates). Disponível em: < https://www.youtube.com/ watch?v=o4YY4X3eMHQ>. Acesso em: 12 dez. 2015.
AQUINO, J. R. et al. Caracterização do público potencial do PRONAF "B" na região Nordeste e no estado de Minas Gerais: uma análise baseada nos dados do Censo Agropecuário 2006. Porto Alegre: UFRGS/IPEA, 2013. (Relatório de Pesquisa). Disponível em: <http://www.ipea.gov.br/ portal/images/stories/PDFs/relatoriopesquisa/130319 relatorio_caracterizacao_publico.pdf $>$. Acesso em: 10 jan. 2014.

AQUINO, J. R. e SCHNEIDER, S. O PRONAF e o desenvolvimento rural brasileiro: avanços, contradições e desafios para o futuro. In: GRISA, C. e SCHNEIDER, S. (Orgs.). Políticas públicas de desenvolvimento rural no Brasil. Porto Alegre: Ed. da UFRGS, 2015. p. 53-81.

ARAÚJO, T. B. Herança de diferenciação e futuro de fragmentação. Estudos Avançados, São Paulo/USP, v. 11, n. 29, p. 7-36, 1997.

BELIK, W. O financiamento da agropecuária brasileira no período recente. In: CALIXTRE, A. B., BIANCARELLI, A. M. e CINTRA, M. A. M. (Eds.). Presente e futuro do desenvolvimento brasileiro. Brasília: IPEA, 2014. p. 329-374.

. A heterogeneidade e suas implicações para as políticas públicas no rural brasileiro. Revista de Economia e Sociologia Rural, Piracicaba/SP, v. 53, n. 1, p. 9-30, jan./ mar. 2015.

BIANCHINI, V. Vinte anos do PRONAF, 1995-2015: avanços e desafios. Brasília: SAF/MDA, 2015.

BRUNO, R. Movimento "Sou Agro": marketing, habitus e estratégias de poder do agronegócio. Composição: Revista de Ciências Sociais da Universidade Federal de Mato Grosso do Sul, v. 8, n. 14, p. 85-85, jun. 2014.

BUAINAIN; A. M. e DEDECCA, C. S. Mudanças e reiteração da heterogeneidade do mercado de trabalho. In: GASQUES, J. G., VIEIRA FILHO, J. E. e NAVARRO, Z. (Orgs.). A agricultura brasileira: desempenho, desafios e perspectivas. Brasília: IPEA, 2010, p. 123-153.

BUAINAIN, A. M. et al. Sete teses sobre o mundo rural brasileiro. Revista de Política Agrícola, Brasília/DF, ano XXII, n. 2, p. 105-121, abr./jun. 2013.

CAMARGO, R. A. L. e OLIVEIRA, J. T. A. Agricultura familiar e não-familiar: um olhar sobre a complexidade de relações no mundo rural. In: CONGRESSO DA SOCIEDADE BRASILEIRA DE ECONOMIA, ADMINISTRAÇÃO E SOCIOLOGIA RURAL, 49., Belo Horizonte/MG. Anais... Belo Horizonte/MG: SOBER, 2011. 20p. (CD-ROM).

CAMPOS, S. C. e NAVARRO, Z. (Orgs.). A pequena produção rural e as tendências do desenvolvimento agrário brasileiro: ganhar tempo é possível? Brasília/DF: CGEE, 2013. 
CEPAL/FAO/IICA. Perspectivas de la agricultura y del desarrollo rural en las Américas: una mirada hacia América Latina y el Caribe 2014 (Resumen Ejecutivo). [S.1.]: CEPAL/FAO/IICA, 2013. 62p. Disponível em: <http://repiica.iica.int/docs/b3165e/b3165e.pdf>. Acesso em: 3 out. 2013.

COUTO, V. A., DUfUMIER, M. e REIS, L. L. M. Agronegócio e agricultura familiares: crítica do discurso único para dois brasis. Salvador: UFBA, 2013.

COUTO, V. A. Agriculturas e agricultores familiares. Bahia \& Análise de Dados, Salvador/BA, v. 24, n. 2, p. 247257, abr.jun. 2014.

DEL GROSSI, M. E. e MARQUES, V. P. M. A. Agricultura familiar no censo agropecuário 2006: o marco legal e as opções para sua identificação. Estudos Sociedade $e$ Agricultura, Rio de Janeiro, v. 18, n. 1, p. 127-157, abr. 2010.

DEL GROSSI, M. E. Agricultura familiar no Censo Agropecuário 2006. (Documento em formato PowerPoint apresentado no 49으. Congresso da Sociedade Brasileira de Economia, Administração e Sociologia Rural, realizado na cidade de Belo Horizonte/MG, 2011).

DELGADO, G. C. O setor de subsistência na economia brasileira: gênese histórica e formas de reprodução. In: JACCOUD, L. (Org.). Questão social e politicas sociais no Brasil contemporâneo. Brasília: IPEA, 2005. p. 19-50.

. Do capital financeiro na agricultura à economia do agronegócio: mudanças cíclicas em meio século (19652012). Porto Alegre: Editora da UFRGS, 2012.

DIEESE. Estatísticas do meio rural 2010-2011. 4. ed. São Paulo: DIEESE/NEAD-MDA, 2011.

ESQUERDO, V. F. S. e BERGAMASCO, S. M. Balanço sobre a reforma agrária brasileira nas duas últimas décadas. Interciencia, Caracas/Venezuela, v. 38, n. 8, p. 563-569, ago. 2013.

FAO. Family farmers feeding the world, caring for the Earth. Rome: FAO, 2014a. 4p.

. Deep Roots. Rome: FAO, 2014b. 257p. 2015. 30p.

Global Dialogue on Family farms. Rome: FAO.

FAO/INCRA.Diretrizesdepolíticaagráriaedesenvolvimento sustentável. Resumo do Relatório Final do Projeto UTF/ BRA/036, segunda versão. Brasília, 1995.

Perfil da agricultura familiar no Brasil: dossiê estatístico. Projeto UFT/BRA/036/BRA, ago. 1996.

. Novo retrato da agricultura familiar: o Brasil redescoberto. Brasília, 2000.
FERNANDES, B. M. Questão agrária e capitalismo agrário: o debate paradigmático de modelos de desenvolvimento no campo. Reforma Agrária - Revista da Associação Brasileira de Reforma Agrária (ABRA), ano 35, v. 1, n. 2, p. 41-53, out. 2014.

FRANÇA, C. G., DEL GROSSI, M. E. e MARQUES, V. P. M. A. O Censo Agropecuário 2006 e a agricultura familiar no Brasil. Brasília: MDA, 2009.

GARCIA, F., HELFAND, S. e SOUZA, A. P. Transferências monetárias condicionadas y políticas de desarrollo rural en Brasil: posibles sinergias entre Bolsa Família y el Pronaf. In: MALDONADO, J. H. et al. (Orgs.). Protección, producción, promoción: explorando sinergias entre protección social y fomento productivo rural en América Latina. Bogotá: Universidad de los Andes/ Facultad de Economía/CEDE/FIDA, 2016. p. 69-115.

GASQUES, J. G. et al. Produtividade Total dos Fatores e transformações da agricultura brasileira: análise dos dados dos censos agropecuários. In: GASQUES, J. G., VIEIRA FILHO, J. E. e NAVARRO, Z. (Orgs.). A agricultura brasileira: desempenho, desafios e perspectivas. Brasília: IPEA, 2010. p. 19-44.

GAZOLLA, M. e SCHNEIDER, S. Qual "fortalecimento" da Agricultura Familiar? Uma análise do Pronaf crédito de custeio e investimento no Rio Grande do Sul. Revista de Economia e Sociologia Rural, Piracicaba-SP, v. 51, n. 1, p. 47-70, jan./mar. 2013.

GRAZIANO DA SILVA, J. O marketing do conflito: agricultura familiar $X$ agronegócio no Brasil do século XXI. In: CONGRESSO BRASILEIRO DE ECONOMIA, ADMINISTRAÇÃO E SOCIOLOGIA RURAL, 47., 2009, Porto Alegre/RS. Anais... Porto Alegre/RS: SOBER, 2009.

. Os desafios das agriculturas brasileiras. In: GASQUES, J. G., VIEIRA FILHO, J. E. e NAVARRO, Z. (Orgs.). A agricultura brasileira: desempenho, desafios e perspectivas. Brasília: IPEA, 2010, p. 157-183.

GUANZIROLI, C. H., BUAINAIN, A. M. e DISABBATO, A. Dez anos de evolução da agricultura familiar no Brasil: (1996 e 2006). Revista de Economia e Sociologia Rural, Piracicaba-SP, v. 50, n. 2, p. 351-370, abr.jun. 2012.

HELFAND, S. e PEREIRA, V. Determinantes da pobreza rural e implicações para as políticas públicas no Brasil. In: BUAINAIN, A. M. et al. (Orgs.). A nova cara da pobreza rural: desafios para as políticas públicas. Brasília: IICA, 2012. p. 121-159.

HELFAND, S., PEREIRA, V. F. e SOARES, V. L. Pequenos e médios produtores na agricultura brasileira: situação atual e perspectivas. In: BUAINAIN, A. M. et al. (Eds.). O mundo rural no Brasil do século 21: a formação de um 
novo padrão agrário e agrícola. Brasília/DF: EMBRAPA, 2014. p. 533-557.

HOFFMANN, R. e NEY, M. G. Evolução recente da estrutura fundiária e propriedade rural no Brasil. In: GASQUES, J. G., VIEIRA FILHO, J. E. e NAVARRO, Z. (Orgs.). A agricultura brasileira: desempenho, desafios e perspectivas. Brasília: IPEA, 2010. p. 45-64.

HOFFMANN, R. A agricultura familiar produz $70 \%$ dos alimentos consumidos no Brasil? Segurança Alimentar e Nutricional, Campinas-SP, v. 21, n. 1, p. 417-421, 2014.

IBGE. Censo Agropecuário 2006. Agricultura Familiar. Primeiros resultados. Brasil, Grandes Regiões e Unidades da Federação. Brasília/Rio de Janeiro: MDA/MPOG, 2009.

. Censo Agropecuário 2006: Brasil, grandes regiões e unidades da federação - segunda apuração. Rio de Janeiro: MPOG/IBGE, 2012.

. Nota Informativa: corte no orçamento inviabiliza realização do Censo Agropecuário em 2017. Rio de Janeiro: IBGE, 2016. Disponível em: < http://www.ibge. gov.br/home/disseminacao/destaques/2016_04_18_ comunicado_censo_agropecuario.shtm $>$. Acesso em: 18 abr. 2016.

IBGE/SIDRA. Censo Agropecuário 2006: agricultura familiar - MDA/PRONAF (Lei no 11.326 de 24/07/2006). RJ: IBGE, 2012. Disponível em: <http://www. sidra.ibge.gov.br/bda/pesquisas/ca/defaultMDA. $\operatorname{asp} ? \mathrm{z}=\mathrm{p} \& \mathrm{o}=2 \& \mathrm{i}=\mathrm{P}>$.Acesso em: 26 out. 2015.

KAGEYAMA, A. A., BERGAMASCO, S. M. P. P. e OLIVEIRA, J. A. Uma tipologia dos estabelecimentos agropecuários do Brasil a partir do Censo 2006. Revista de Economia e Sociologia Rural, Piracicaba-SP, v. 51, n. 1, p. 105-122, jan./mar. 2013.

LAMARCHE, H. (Coord.). Agricultura familiar: comparação internacional. Campinas, SP: Editora da UNICAMP, 1993. (Volume 1).

LEPORATI, M. et al. La agricultura familiar em cifras. In: SALCEDO, S. e GUSMÁN, L. (Eds.). Agricultura familiar en América Latina y el Caribe. Santiago/Chile: FAO, 2014. p. 35-56.

LONG, N. e PLOEG J. D. van der. Heterogeneity, actor and structure: towards a reconstitution of the concept of structure. In: BOOTH, D. (Ed.). Rethinking social development: theory, research and practice. England: Longman, 1994. p. 62-90.

LOWDER, S. K., SKOET, J. e SINGH, S. What do we really know about the number and distribution of farms and family farms worldwide? Background paper for The State of Food and Agriculture 2014. Rome: FAO, 2014. 45p. (ESA Working Paper No. 14-02).
LOWDER, S. K., SKOET, J. e RANEY, T. The number, size, and distribution of farms, smallholder farms, and family farms worldwide. World Development, p. 1-14, 2016. Disponível em: <http://dx.doi.org/10.1016/j. worlddev.2015.10.041 >. Acesso em: 20 mar. 2016.

MATTEI, L. Mudanças nas regras de financiamento do PRONAF. Artigos mensais OPPA. Rio de Janeiro/UFRRJ/ CPDA, n. 17, p. 1-4, mar. 2008.

. O papel e a importância da agricultura familiar no desenvolvimento rural brasileiro contemporâneo. Revista Econômica do Nordeste, Fortaleza, v. 45, p. 71-79, 2014a.

. Considerações acerca de teses recentes sobre o mundo rural brasileiro. Revista de Economia e sociologia Rural, Piracicaba-SP, v. 52, supl. 1, p. 105-124, 2014 b.

. O governo interino e a desestruturação da política agrária e de desenvolvimento rural do país. Santa Catarina: NECAT/UFSC, 2016. 14p. (Texto p/ Discussão, n⿳丷ㅜ18).

MDA. Agricultura familiar. Brasília: MDA, 2014. Disponível em: <http://www.mda.gov.br>. Acesso em: 10 dez. 2014.

. Brasil rural: mais justo e igual. Brasília: MDA, 2016. Disponível em: <http://www.mda.gov.br/ sitemda/noticias/brasil-rural-mais-igual-e-justo $>$. Acesso em: 25 fev. 2016.

MDA/SAF/PRONAF. Plano safra da agricultura familiar 2006/2007. Brasília: MDA/SAF, 2006. Disponível em: <http://www.mda.gov.br> Acesso em: 22 nov. 2006.

. Cartilha do Plano Safra da Agricultura Familiar 2013-2014. Brasília: MDA, 2013. Disponível em: <www. mda.gov.br>. Acesso em: 04 set. 2013.

NAVARRO, Z. e PEDROSO, M. T. M. A agricultura familiar no Brasil: da promessa inicial aos impasses do presente. Revista Econômica do Nordeste, Fortaleza, v. 45, p. 6-17, 2014.

NERI, M. C., MELO, L. C. C. e MONTE, S. R. S. Superação da pobreza e a nova classe média no campo. Brasília: MDA/ NEAD, 2012.

NEVES, D. P. Agricultura familiar: quantos ancoradouros! In: FERNANDES, B. M., MARQUES, M. I. M. e SUZUKI, J. C. (Orgs.). Geografia agrária: teoria e poder. São Paulo: Expressão Popular, 2007. p. 211-270.

NIEDERLE, P. A., FIALHO, M. A. V. e CONTERATO, M. A. A pesquisa sobre agricultura familiar no Brasil: aprendizagens, esquecimentos e novidades. Revista de Economia e Sociologia Rural, Piracicaba-SP, v. 52, supl. 1, p. 9-24, 2014. 
PICOLOTTO, E. L. Reconhecimento da agricultura familiar e as disputas pela classe média rural. Revista Espaço Acadêmico, [S.1.], ano XI, n. 128, p. 158-167, jan. 2012.

. Os atores da construção da categoria agricultura familiar no Brasil. Revista de Economia e Sociologia Rural, Piracicaba-SP, v. 52, supl. 1, p. 63-84, 2014.

SAF/MDA. Agricultura familiar e o "campo de oportunidades". Brasília: SAF/MDA, set. 2015. 13p. (Texto $\mathrm{p} /$ Discussão).

SCHNEIDER, S. e XAVIER, L. (Coords.). Análise multidimensional dos dados do novo Censo Agropecuário de 2006 (Projeto de Cooperação Técnica Ipea/PGDR 20102011). Porto Alegre: PGDR/ UFRGS, 2010. Disponível em: $\quad<$ http://www1.ufrgs.br/pesquisa/forms/form dadosProjetoPesquisa.php?Cod $=19616 \& N r S e q B o l s a=$ $\&$ CodProjeto=> . Acesso em: 20 jun. 2011.

SCHNEIDER, S. e CASSOL, A. Diversidade e heterogeneidade da agricultura familiar no Brasil e algumas implicações para as políticas públicas. Cadernos de Ciência E Tecnologia, Brasília, v. 31, n. 2, p. 227-263, maio/ago. 2014.

SEIBT, P. et al. Anuário brasileiro da agricultura familiar 2015. Erechim/RS: Ed. Bota Amarela, 2015.

SOARES, P. R. B. Censo Agropecuário 2006: possibilidades de uso e o que demonstram os dados. In: RODOMSKY, G. F. W., CONTERATO, M. A. e SCHNEIDER, S. (Orgs.). Pesquisa em desenvolvimento rural: técnicas, bases de dados e estatísticas aplicadas aos estudos rurais. Porte Alegre: Editora da UFRGS, 2015. p. 109-126. (Volume 2).

VEIGA, J. E. O desenvolvimento agrícola: uma visão histórica. São Paulo/SP: Hucitec, 1991.

WANDERLEY, M. N. B. O campesinato brasileiro: uma história de resistência. Revista de Economia e Sociologia Rural, Piracicaba-SP, v. 52, supl. 1, p. 25-44, 2014.

Todo o conteúdo deste periódico, exceto onde estiver identificado, está licenciado sob uma Licença Creative Commons (cc by 4.0 ) 
